\title{
Neonatal Diarrhea, AE
}

National Cancer Institute

\section{Source}

National Cancer Institute. Neonatal Diarrhea, AE. NCI Thesaurus. Code C154953.

An adverse event in a newborn characterized by watery bowel movements. 